Supporting Information for

\title{
Aquatic Photochemistry of Nitrofuran Antibiotics
}

Betsy L. Edhlund $d^{\dagger}$, William A. Arnold ${ }^{\ddagger *}$, and Kristopher McNeill ${ }^{\dagger, *}$

${ }^{\dagger}$ Department of Chemistry, University of Minnesota, 207 Pleasant Street SE, Minneapolis, Minnesota 55455

Department of Civil Engineering, University of Minnesota, 500 Pillsbury Street SE, Minneapolis, MN 55455

Section S1. Chemicals and nitrofuran antibiotic physicochemical properties.

Pages

Section S2. Analytical Methods

S2-S3

Section S3. Photodegradation of FZD in $\mathrm{pH} 7$ buffer with and without $0.2 \mathrm{M} \mathrm{Cl}^{-}$.

Section S4. UV-Vis spectra of parent and isomer FTD and NFT.

Section S5. $\mathrm{pH}$ dependence on the rate constant for the photodegradation of FZD.

Section S6. Stern-Volmer plots for nitrofurans. Measurements performed in $\mathrm{D}_{2} \mathrm{O}$ for FTD and ACN for FZD and NFT. The lines are derived from linear regression analysis, $k_{\mathrm{obs}}=k_{\mathrm{solv}}+k_{\mathrm{tot}}[\mathrm{S}]$, and the slope $=k_{\text {tot }}$.

Section S7. Direct photolysis degradation of nitrofurans and degradation of nitrofurans and the reference compound furaldehyde due to reaction with singlet oxygen versus time.

Section S8. Competitive hydroxyl radical oxidation of nitrofurans versus the reference compound acetophenone using Fenton's reagent.

Section S9. Change in $\left[\mathrm{H}^{+}\right]$during photolysis of NFT in DI $\mathrm{H}_{2} \mathrm{O}$ and LJW.

Section S10. Action spectra for FTD, FZD, NFT, and ranitidine and spectral overlap of sunlight emission and FZD absorbance. 


\section{Section S1. Chemicals}

Furaltadone hydrochloride (FTD), furazolidone (FZD), and sodium nitrite were purchased from Sigma. Pyridine, 2-nitrofuran, 2-furfural, $\mathrm{NaOH}$, and Rose Bengal were purchased from Aldrich. Nitrofurantoin (NFT) was obtained from MP Biomedicals. Morton's brand $\mathrm{NaCl}$ was used. Hydrochloric acid was purchased from Mallickrodt Chemicals. Potassium phosphate, monobasic and sodium phosphate, dibasic were obtained from J.T. Baker and FisherBiotech, respectively. Acetophenone and $p$-nitroanisole were purchased from Acros; 5-Nitrofuraldehyde (NFA) was obtained from Fluka. All chemicals were used as received. All solvents were of HPLC grade. FTD, FZD, and NFT were analyzed by HPLC and NMR and appeared to be $>99 \%$ pure by these measures.

Table S1. Physicochemical Properties of Furaltadone, Furazolidone, and Nitrofurantoin.

\begin{tabular}{|c|c|c|c|}
\hline & Furaltadone & Furazolidone & Nitrofurantoin \\
\hline CAS & $139-91-3$ & $67-45-8$ & $67-20-9$ \\
\hline Molecular weight $(\mathrm{g} / \mathrm{mol})$ & 324.29 & 225.16 & 238.16 \\
\hline Melting point $\left({ }^{\circ} \mathrm{C}\right)$ & 206 & 256 & 268 \\
\hline $\mathrm{pK}_{\mathrm{a}}$ & $6.56(1)$ & $3.12(2)$ & $1.2,7.7(3)$ \\
\hline${\text { Estimated } \mathrm{ow}^{a}}^{a}$ & 0.25 & 1.02 & -0.17 \\
\hline
\end{tabular}

${ }^{a}$ Estimated using the modeling program KOWWIN version 1.66 provided by the Environmental Protection Agency.

\section{Section S2. Analytical Methods.}

HPLC Analysis. HPLC analyses were performed on an 1100 Series Agilent liquid chromatograph equipped with a UV-absorbance detector or multiwavelength diode array detector. The nitrofuran antibiotics were analyzed with a Supelco RP Amide $\mathrm{C}_{16}, 150 \times 4.6 \mathrm{~mm}$, $5 \mu \mathrm{m}$ particle size column. The mobile phase was a 20:80 mixture of methanol $(\mathrm{MeOH})$ and water $\left(\mathrm{H}_{2} \mathrm{O}\right)$ with a flow rate of $1.0 \mathrm{~mL} / \mathrm{min}$, an injection volume of $10 \mu \mathrm{L}$, and a detection wavelength of $365 \mathrm{~nm}$. The analysis of NFA used the same column with a mobile phase of 50:50 MeOH and $\mathrm{H}_{2} \mathrm{O}$, an injection volume of $20 \mu \mathrm{L}$, and $313 \mathrm{~nm}$ as the detection wavelength. The PNA actinometer was analyzed on a Supelcosil LC-18-DB, $150 \times 4.6 \mathrm{~mm}, 5 \mu \mathrm{m}$ particle size column. The mobile phase for the PNA actinometer was a $70: 30$ acetonitrile $\left(\mathrm{CH}_{3} \mathrm{CN}\right): \mathrm{pH}$ $5 \mathrm{NH}_{4} \mathrm{OAc}$ buffered water mixture with a flow rate of $1.0 \mathrm{~mL} / \mathrm{min}$, an injection volume of $10 \mu \mathrm{L}$, and a detection wavelength of $313 \mathrm{~nm}$.

UV-Vis Absorbance Measurements of Photoisomers. The UV-Vis spectra of the parent nitrofuran antibiotics and the isomers were obtained on an 1090 Series Hewlett Packard liquid chromatograph equipped with a photodiode array (PDA) detector. A Supelco RP Amide $\mathrm{C}_{16}$, $150 \times 4.6 \mathrm{~mm}, 5 \mu \mathrm{m}$ particle size column was used with a flow rate of $1.0 \mathrm{~mL} / \mathrm{min}$ and an injection volume of $20 \mu \mathrm{L}$. Gradient elution was employed. For FTD, the mobile phase consisted of a 15:85 MeOH: $\mathrm{H}_{2} \mathrm{O}$ mixture which ramped to $45: 55 \mathrm{MeOH}: \mathrm{H}_{2} \mathrm{O}$ over 6 minutes and back to initial conditions in 0.01 minutes. The initial mobile phase mixture for FZD was 20:80 $\mathrm{MeOH}: \mathrm{H}_{2} \mathrm{O}$ with a ramp to $50: 50 \mathrm{MeOH}: \mathrm{H}_{2} \mathrm{O}$, and $25: 75 \mathrm{MeOH}: \mathrm{H}_{2} \mathrm{O}$ with a ramp to 55:45 $\mathrm{MeOH}: \mathrm{H}_{2} \mathrm{O}$ for NFT. The gradient times were the same for these compounds as for FTD.

LC-MS Analysis. Mass spectra for isomer confirmation and UV-Vis of nitrofuraldehyde were obtained using a Spectra System LC P400 equipped with a PDA detector connected to a 
ThermoElectron LCQ Classic ion trap mass spectrometer (ESI in positive ion mode). A Supelco RP Amide $\mathrm{C}_{16}, 150 \times 4.6 \mathrm{~mm}, 5 \mu \mathrm{m}$ particle size column was used with a flow rate of 1.0 $\mathrm{mL} / \mathrm{min}$ and an injection volume of $50 \mu \mathrm{L}$. The mobile phase was a 20:80 mixture of $\mathrm{MeOH}$ and $\mathrm{H}_{2} \mathrm{O}$ and the PDA detector was set to scan the wavelength range of $200-500 \mathrm{~nm}$.

Section S3. Photodegradation of FZD in $\mathrm{pH} 7$ buffer with and without $0.2 \mathrm{M} \mathrm{Cl}^{-}$.

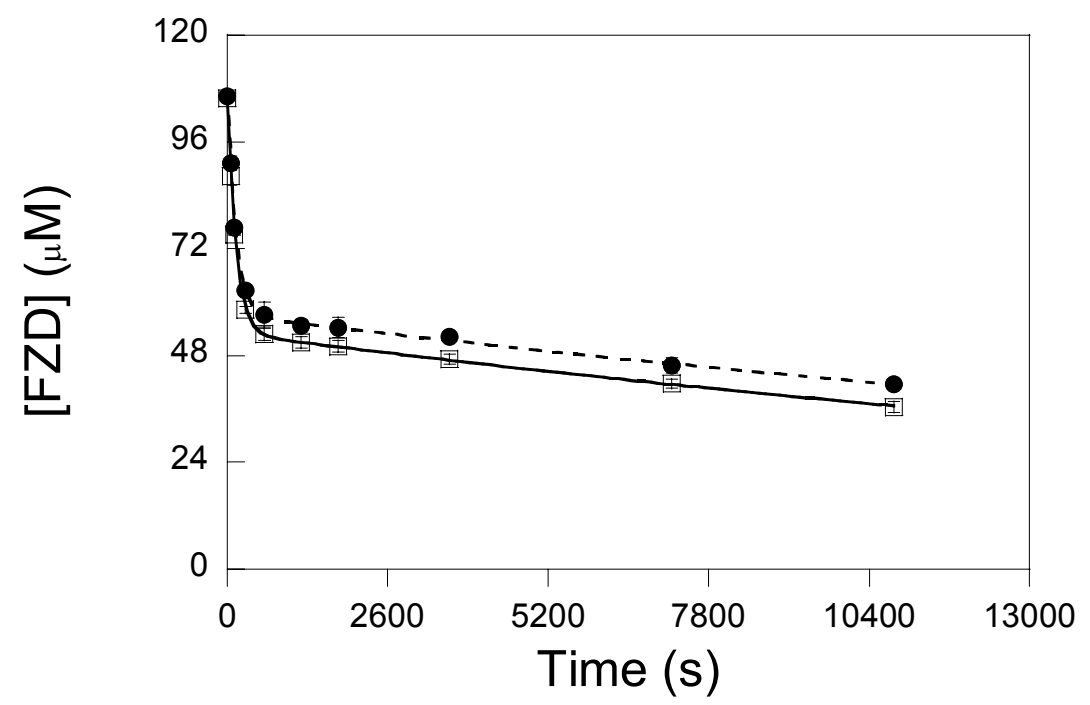

Figure S1. Photodegradation of FZD in $\mathrm{pH} 7$ buffer $(\bullet)$ and $\mathrm{pH} 7$ buffer containing $0.2 \mathrm{M} \mathrm{Cl}^{-}$ (ם), error bars represent the standard deviation of triplicate experiments. Rate constants of degradation were within error of one another.

Section S4. UV-Vis spectra of parent and isomer FTD and NFT.

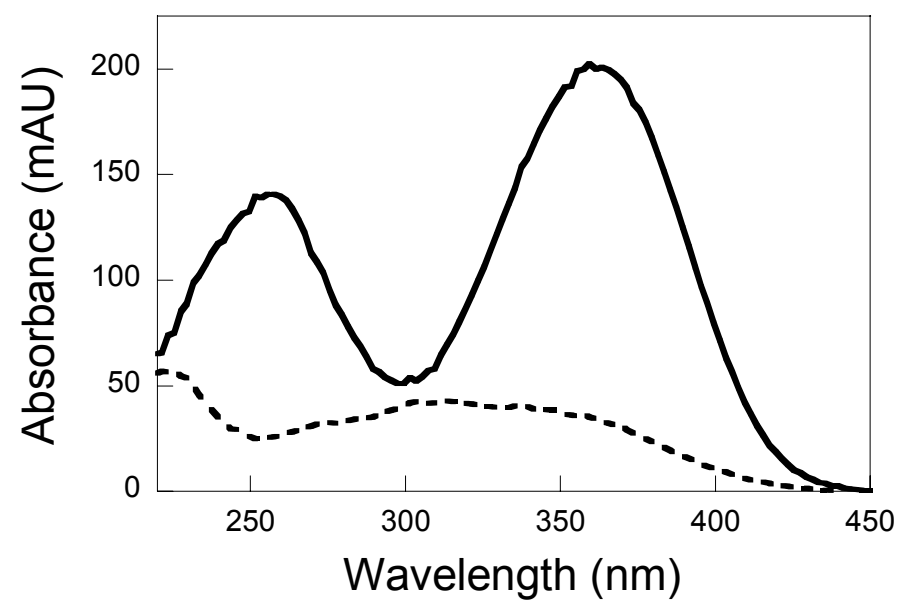

Figure S2. UV-Vis spectra of FTD (- parent compound, --- photoisomer). Spectra were acquired by separating the parent compound and isomer via HPLC; detecting with a diode array detector. 


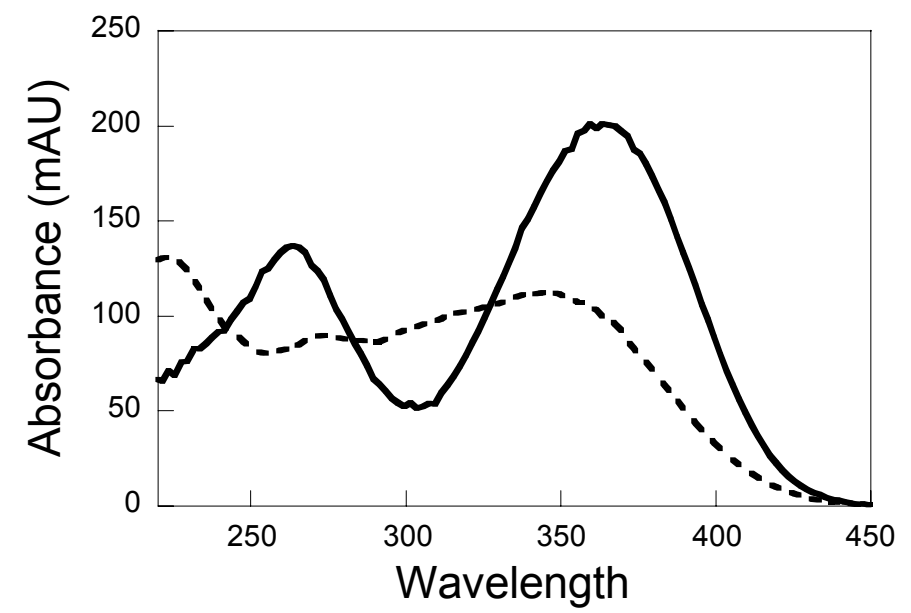

Figure S3. UV-Vis spectra of NFT (- parent compound, --- photoisomer). Spectra were acquired by separating the parent compound and isomer via HPLC; detecting with a diode array detector.

Section S5. $\mathrm{pH}$ dependence on the rate constant for the photodegradation of FZD.

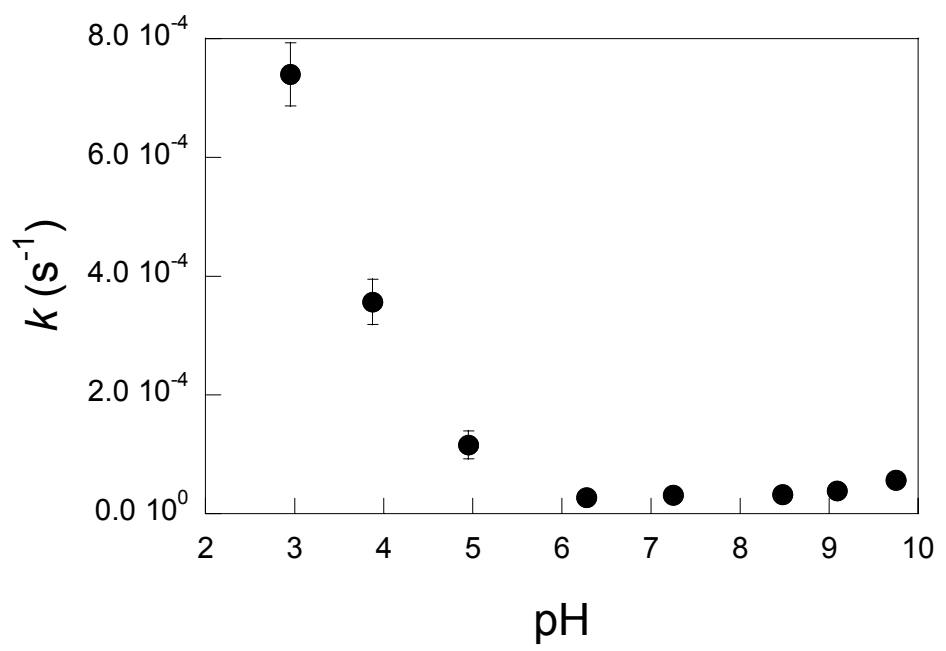

Figure S4. $\mathrm{pH}$ dependence on the rate constant for the photodegradation of $100 \mu \mathrm{M}$ FZD in aqueous $\mathrm{pH}$ buffers. Error bars indicate the standard deviation of triplicate experiments. 
Section S6. Stern-Volmer plots for nitrofurans. Measurements performed in $\mathrm{D}_{2} \mathrm{O}$ for FTD and ACN for FZD and NFT. The lines are derived from linear regression analysis, $k_{\mathrm{obs}}=k_{\mathrm{solv}}+$ $k_{\text {tot }}[\mathrm{S}]$, and the slope $=k_{\text {tot }}$.

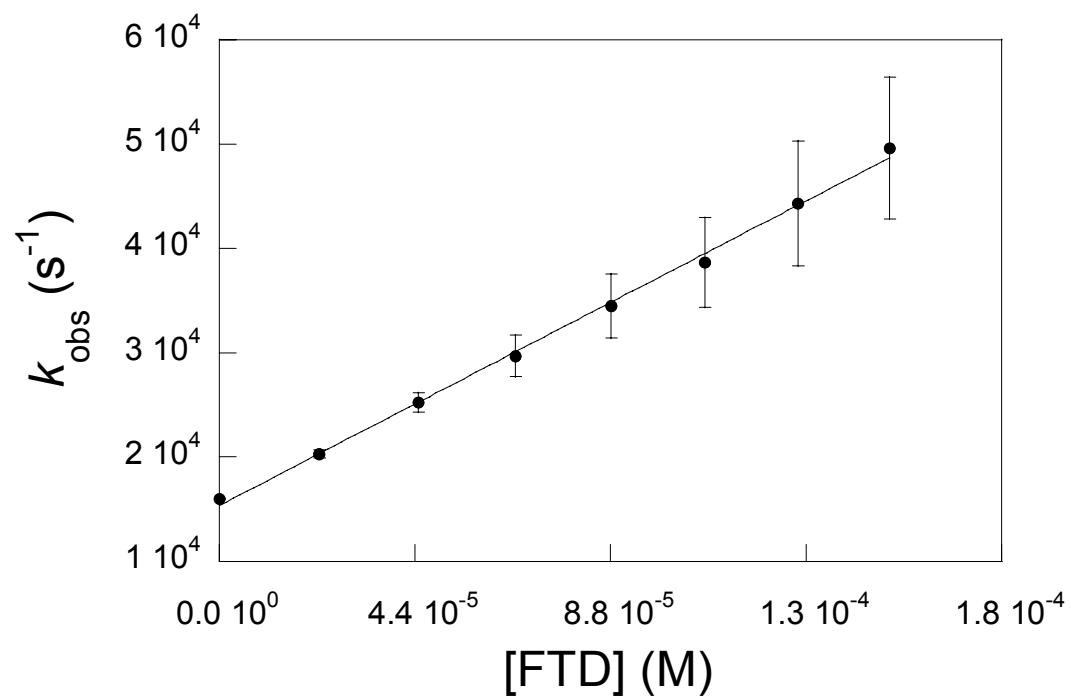

Figure S5. Time resolved phosphorescence quenching data for FTD. The value for $k_{\text {tot }}$ determined from this data is $2 \pm 1 \times 10^{8} \mathrm{M}^{-1} \mathrm{~s}^{-1}$.

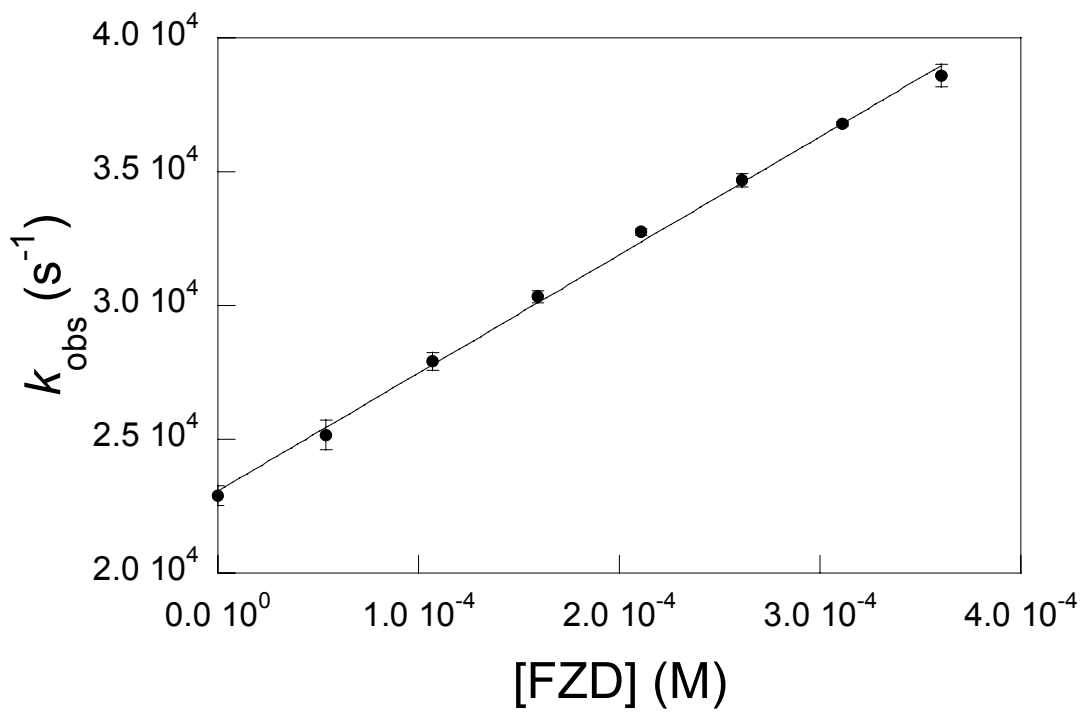

Figure S6. Time resolved phosphorescence quenching data for FZD. The value for $k_{\text {tot }}$ determined from this data is $4.4 \pm 0.2 \times 10^{7} \mathrm{M}^{-1} \mathrm{~s}^{-1}$. 


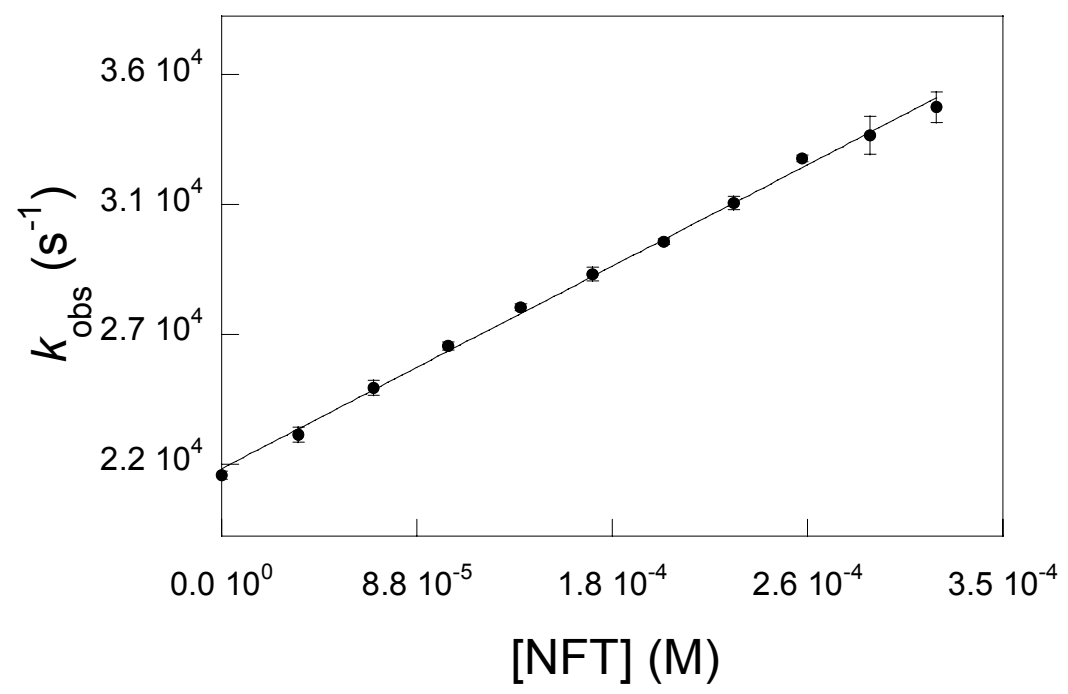

Figure S7. Time resolved phosphorescence quenching data for NFT. The value for $k_{\text {tot }}$ determined from this data is $4.0 \pm 0.5 \times 10^{7} \mathrm{M}^{-1} \mathrm{~s}^{-1}$.

Section S7. Direct photolysis degradation of nitrofurans and degradation of nitrofurans and the reference compound furaldehyde due to reaction with singlet oxygen.

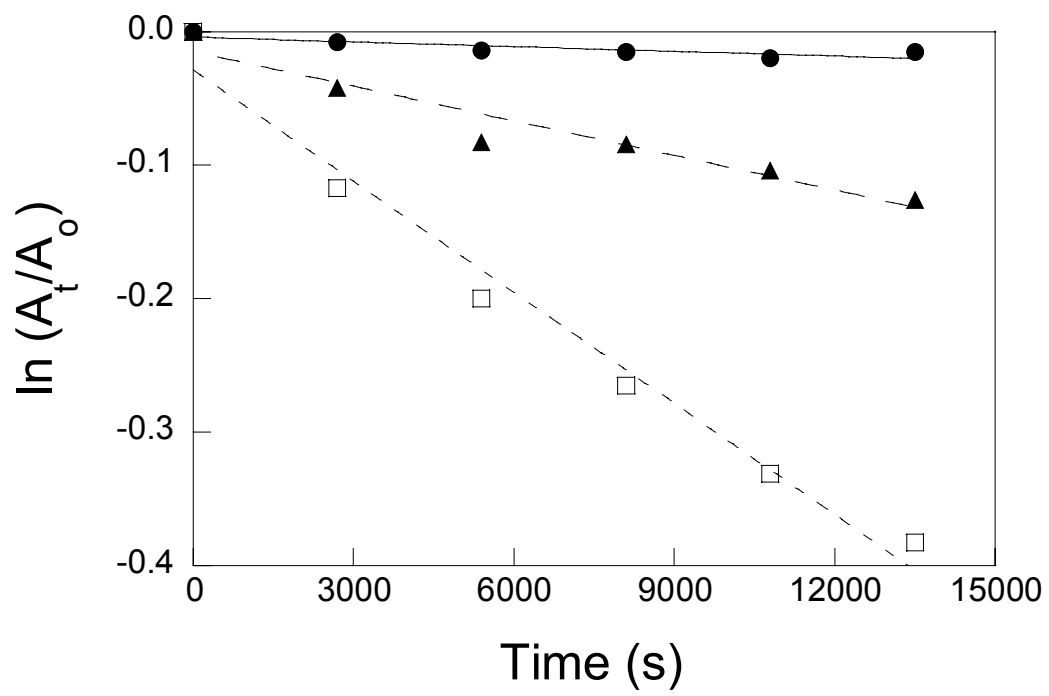

Figure S8. Degradation of FTD due to direct photolysis $(\bullet)$, both direct photolysis and reaction with singlet oxygen $(\square)$, and the reference compound, furaldehyde, due to reaction with singlet oxygen $(\boldsymbol{\Delta})$. From furaldehyde, $\left[{ }^{1} \mathrm{O}_{2}\right]$ was calculated to be $8.11 \times 10^{-12} \mathrm{M}$ and the $k_{\mathrm{r} \times n}$ determined from this data is $(3.3 \pm 0.2) \times 10^{6} \mathrm{M}^{-1} \mathrm{~s}^{-1}$. 


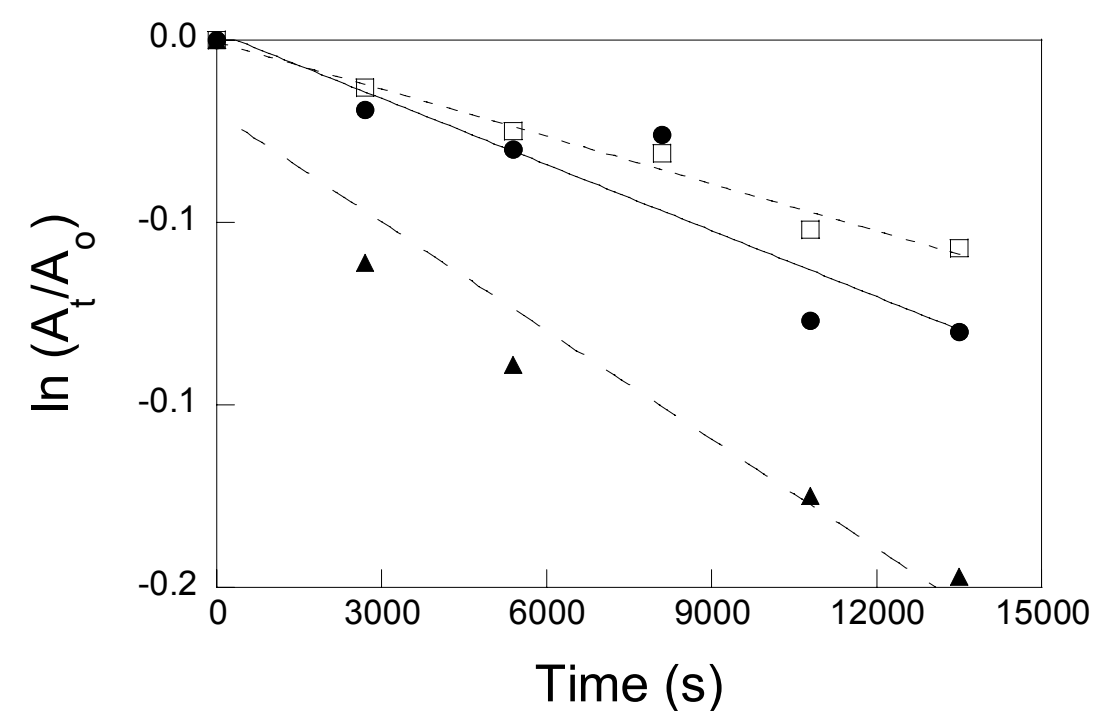

Figure S9. Degradation of FZD due to direct photolysis $(\bullet)$, both direct photolysis and reaction with singlet oxygen $(\square)$, and the reference compound, furaldehyde, due to reaction with singlet oxygen ( $\mathbf{\Delta})$. From furaldehyde, $\left[{ }^{1} \mathrm{O}_{2}\right]$ was calculated to be $9.01 \times 10^{-12} \mathrm{M}$ and the $k_{\mathrm{r} \times n}$ determined from this data is $(5 \pm 2) \times 10^{6} \mathrm{M}^{-1} \mathrm{~s}^{-1}$.

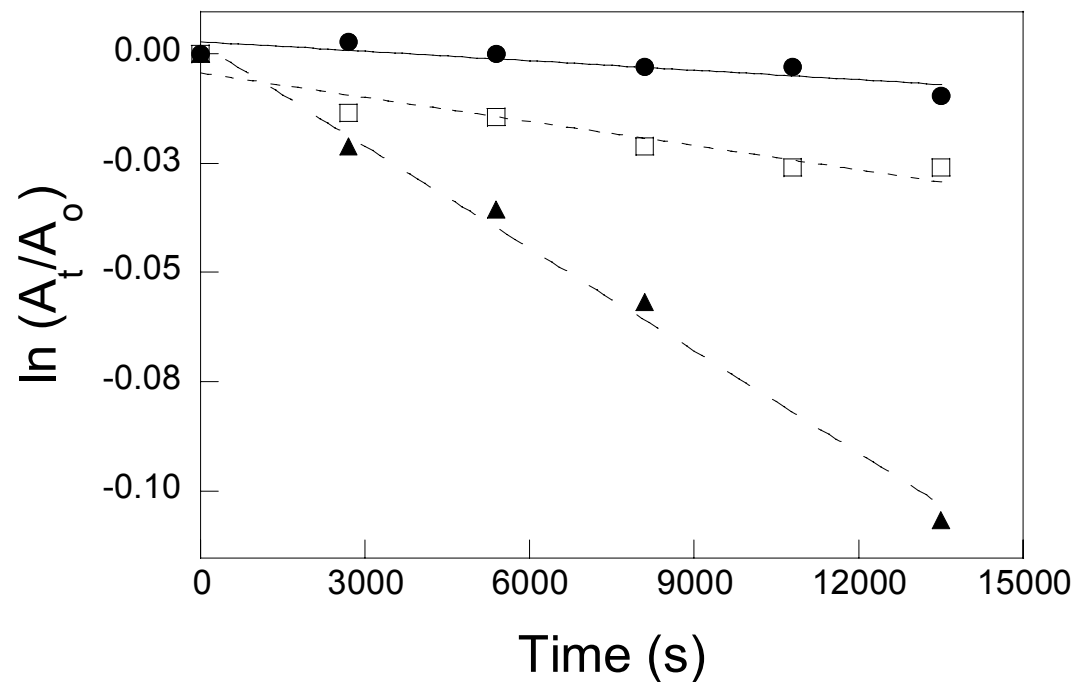

Figure S10. Degradation of NFT due to direct photolysis $(\bullet)$, both direct photolysis and reaction with singlet oxygen $(\square)$, and the reference compound, furaldehyde, due to reaction with singlet oxygen $(\boldsymbol{\Lambda})$. From furaldehyde, $\left[{ }^{1} \mathrm{O}_{2}\right]$ was calculated to be $7.30 \times 10^{-12} \mathrm{M}$ and the $k_{\mathrm{r} \times n}$ determined from this data is $(2 \pm 3) \times 10^{6} \mathrm{M}^{-1} \mathrm{~s}^{-1}$. 
Section S8. Competitive hydroxyl radical oxidation of nitrofurans versus the reference compound acetophenone using Fenton's reagent.

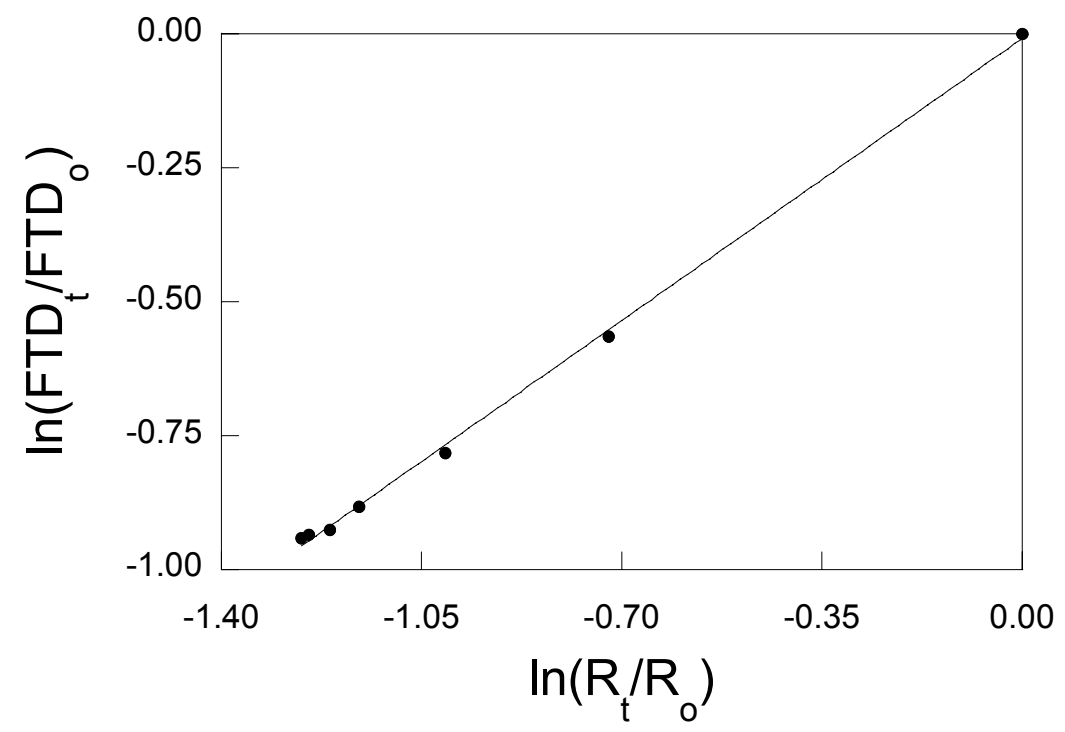

Figure S11. Competitive hydroxyl radical oxidation of FTD versus the reference compound (R, acetophenone, $\left.\mathrm{krxn}=5.9 \times 10^{9} \mathrm{M}^{-1} \mathrm{~s}^{-1}(4)\right)$ using Fenton's reagent. The value for $k_{\mathrm{rxn}}$ determined from this data is $4.7 \pm 0.4 \times 10^{9} \mathrm{M}^{-1} \mathrm{~s}^{-1}$.

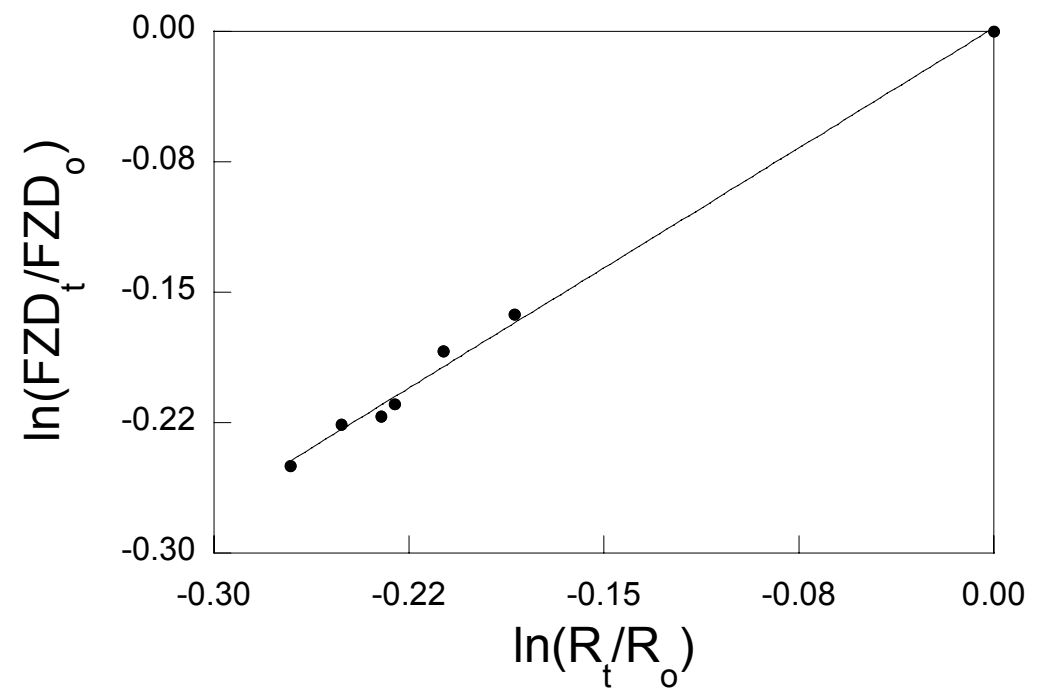

Figure S12. Competitive hydroxyl radical oxidation of FZD versus the reference compound (R, acetophenone, $\left.\mathrm{krxn}=5.9 \times 10^{9} \mathrm{M}^{-1} \mathrm{~s}^{-1}(4)\right)$ using Fenton's reagent. The value for $k_{\mathrm{rxn}}$ determined from this data is $5.2 \pm 0.2 \times 10^{9} \mathrm{M}^{-1} \mathrm{~s}^{-1}$. 


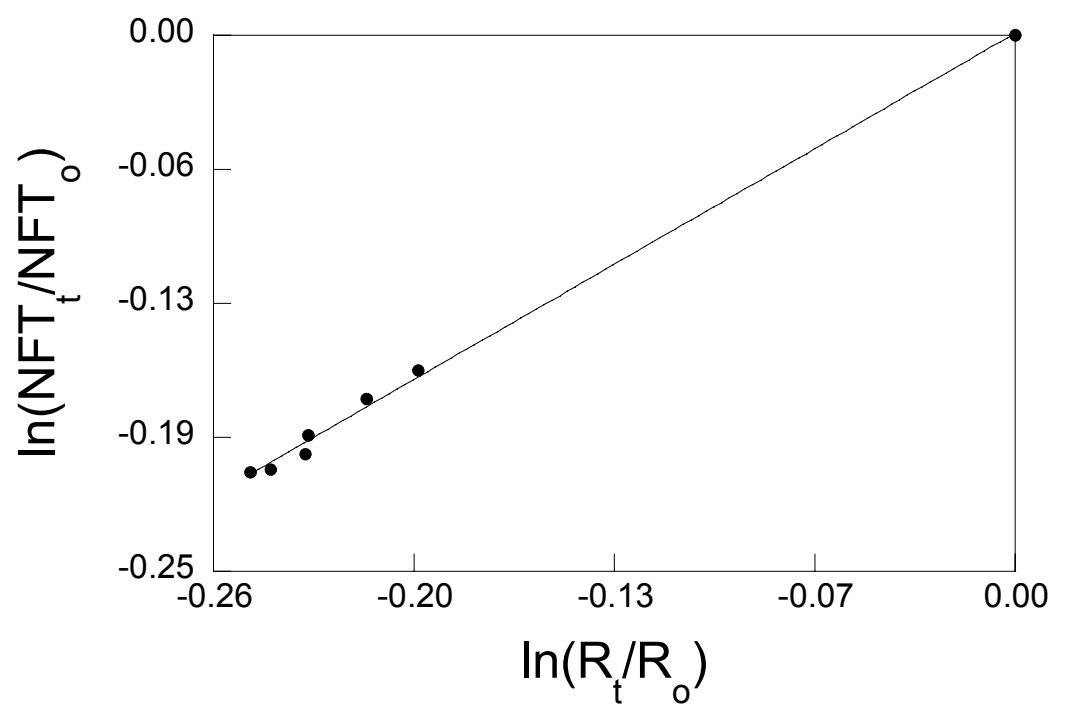

Figure S13. Competitive hydroxyl radical oxidation of NFT versus the reference compound (R, acetophenone, $\left.\mathrm{krxn}=5.9 \times 10^{9} \mathrm{M}^{-1} \mathrm{~s}^{-1}(4)\right)$ using Fenton's reagent. The value for $k_{\mathrm{rxn}}$ determined from this data is $5.1 \pm 0.2 \times 10^{9} \mathrm{M}^{-1} \mathrm{~s}^{-1}$.

Section S9. Change in $\left[\mathrm{H}^{+}\right]$during photolysis of FZD in DI $\mathrm{H}_{2} \mathrm{O}$ and LJW.

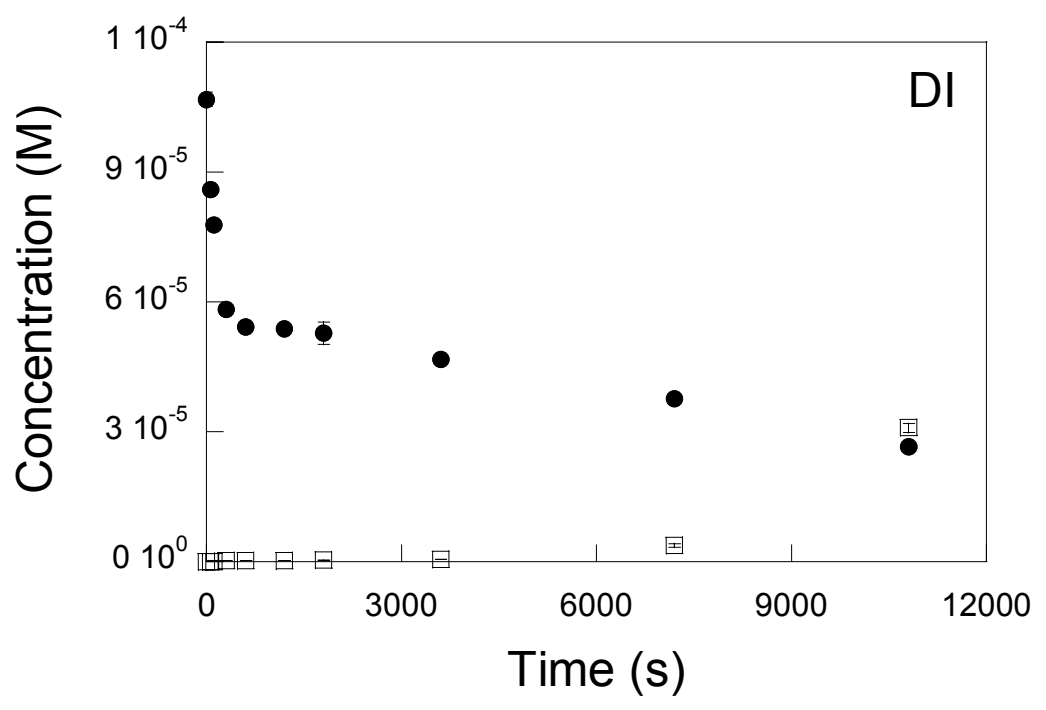




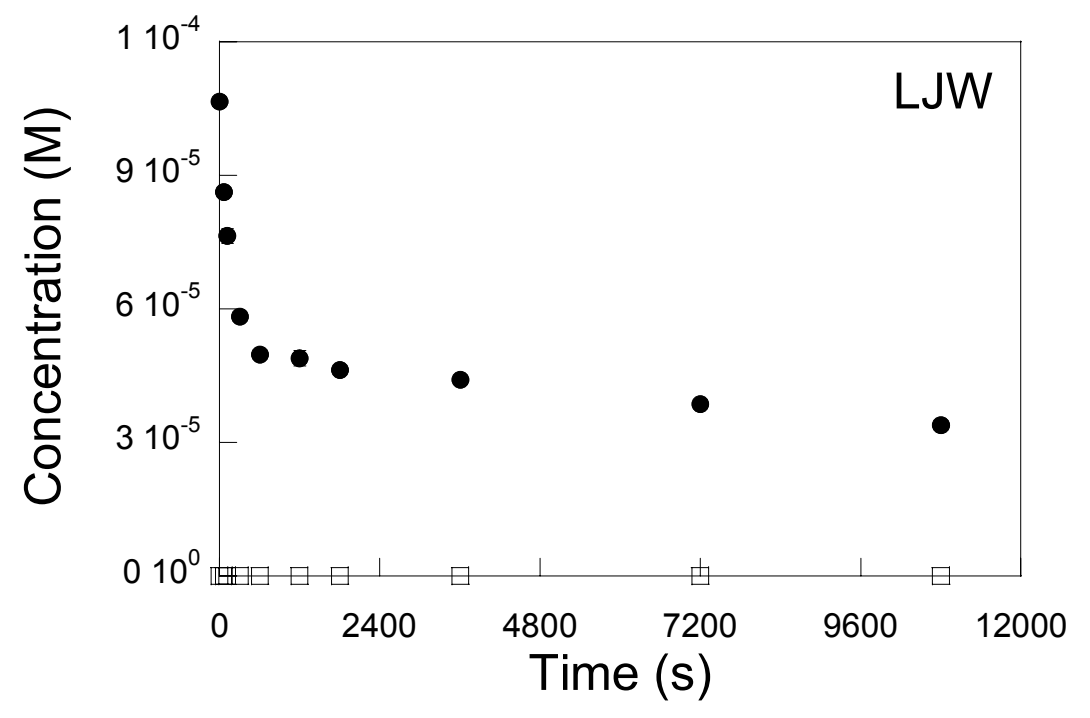

Figure S14. Photodegradation of FZD $(\bullet)$ and growth of $\mathrm{H}^{+}(\square)$ in DI H2O and LJW. No pH change was observed in the LJW sample. Error bars represent the standard deviation of triplicate experiments. 
Section S10. Action spectra for FTD, FZD, NFT, and ranitidine and spectral overlap of sunlight emission and FZD absorbance.
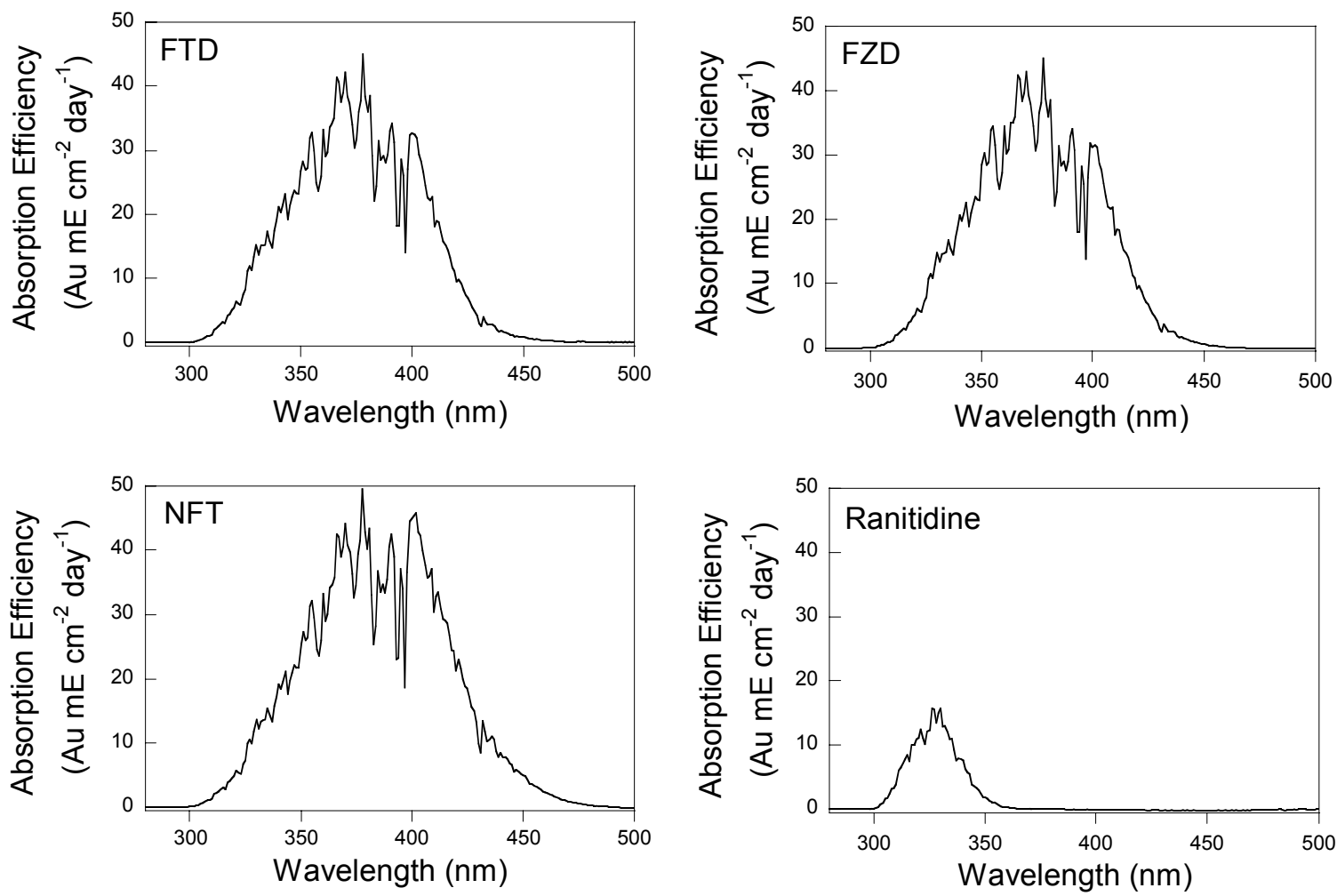

Figure S15. Action spectra for FTD, FZD, NFT, and Ranitidine showing efficiency of solar light absorption of each compound. 


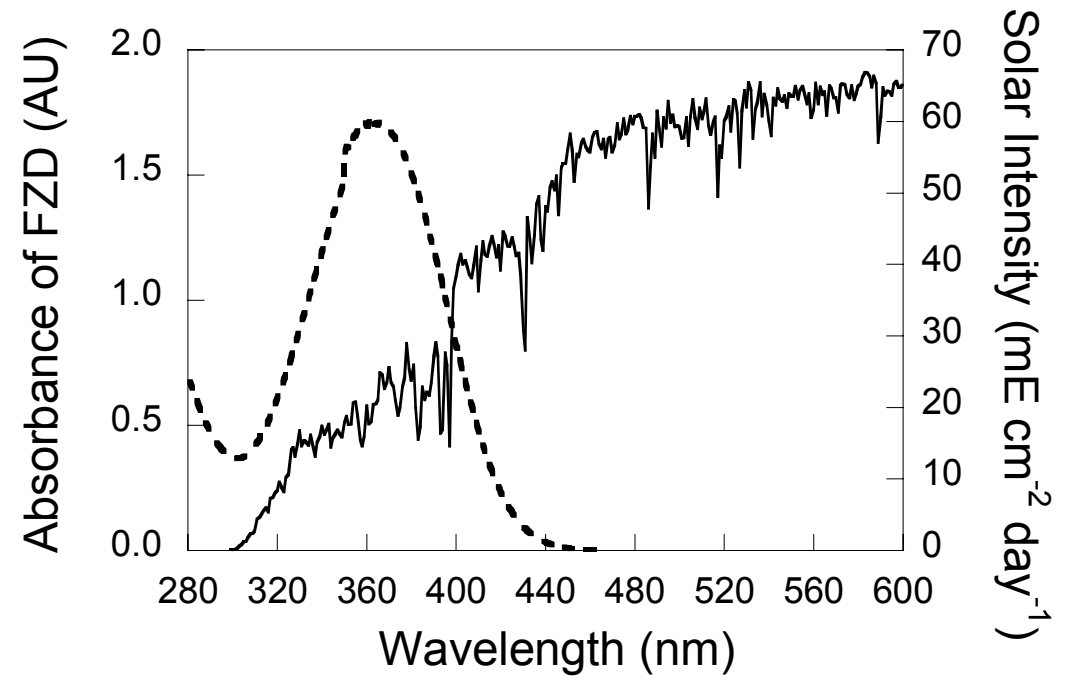

Figure S16. Spectral overlap of sunlight emission and FZD absorbance clearly depicting FZDs ability to absorb considerable sunlight. ( $\mathrm{mE}$ is equal to millieinsteins). FZD absorption indicated by a dashed line (---) and sunlight emission is indicated by a solid line (-). Sunlight emission was calculated using SMARTS for Minneapolis, MN in July at noon $(5,6)$.

\section{Supporting Information References}

(1) The Merck Index. 12th ed.; Entry 4315.

(2) The Merck Index. 12th ed.; Entry 4320.

(3) The Merck Index. 12th ed.; Entry 6696.

(4) Buxton, G. V.; Greenstock, C. L.; Helman, W. P.; Ross, A. B. Critical review of rate constants for reactions of hydrated electrons, hydrogen atoms and hydroxyl radicals (.OH/.O-) in aqueous solution. Journal of Physical and Chemical Reference Data 1988, 17, 513-886.

(5) Gueymard, C. A. SMARTS, A simple model of the atmospheric radiative transfer of sunshine: algorithms and performance assessment.; FSEC-PF-270-95; Florida Solar Energy Center: Cocoa, FL, 1995; $\mathrm{p}^{\wedge} \mathrm{pp}$.

(6) Gueymard, C. A. Parameterized transmittance model for direct beam and circumsolar spectral irradiance. Solar Energy 2001, 71, 325-346. 